\title{
Characteristics of San Francisco Bay Cold-Water Swimmers
}

\section{Biophysical Parameters and Demographic Data, with Analysis of Exercise Patterns, Weight Changes, Safety Concerns, and Perceptions of Cold Tolerance}

\author{
Thomas J. Nuckton ${ }^{*, 1,2,3}$, Elizabeth A. Koehler ${ }^{4}$ and Stephen P. Schatz ${ }^{3}$ \\ ${ }^{I}$ Department of Medicine, California Pacific Medical Center, San Francisco, CA, USA \\ ${ }^{2}$ Department of Medicine, University of California, San Francisco, CA, USA \\ ${ }^{3}$ Dolphin Swimming and Boating Club, San Francisco, CA, USA \\ ${ }^{4}$ Department of Biostatistics, University of North Carolina, Chapel Hill, NC, USA
}

\begin{abstract}
Objectives: To further quantify the characteristics of cold-water swimmers, and to examine the potential exercise benefits, weight changes, perceptions of cold tolerance, and safety concerns related to swimming recreationally in cold water.

Methods: After 3 months (December 21 - March 21) of swimming regularly in cold water in the San Francisco Bay (water temperature range: $9.6^{\circ} \mathrm{C}\left(49.3^{\circ} \mathrm{F}\right)$ to $\left.12.6^{\circ} \mathrm{C}\left(54.7^{\circ} \mathrm{F}\right)\right), 103$ subjects $(76 \mathrm{men}, 27$ women) underwent a detailed biophysical analysis (weight, body mass index, and \% body fat (circumference method)). Swimmers also completed a questionnaire that included questions related to background, exercise patterns, safety, and cold tolerance. To allow for before-and-after comparisons, a sub-group of 50 subjects had biophysical measurements both before, and again after the 3-month winter swim period.

Results: Swimmers were typically in a middle-aged category (mean: $54.3 \pm 10.8$; range: $24-79$, years), employed full-time $(69.9 \%)$, had a recreational swim background $(62.1 \%)$, and had body mass index (BMI) $\left(25.9 \pm 3.6 \mathrm{~kg} / \mathrm{m}^{2}\right)$ and $\%$ body fat $(23.8 \pm 7.5 \%)$ values that were consistent with average American values. The exercise time per week of the subjects (mean: $131.3 \pm 50.8$ minutes/week; median: 120 minutes/week) was significantly greater than an intermediate-intensity value of 100 minutes/week based on American College of Sports Medicine /American Heart Association (ACSM/AHA) recommendations $(\mathrm{P}<0.001)$. Although 27 of 50 before-and-after subjects lost weight (mean weight loss: $2.1 \pm 2.6 \mathrm{~kg}$; range of weight loss: $0.1-10.8 \mathrm{~kg}$ ), subjects overall did not significantly gain or lose weight, or change BMI or $\%$ fat ( $\mathrm{P}>0.1$ for all before-and-after comparisons). The most frequently reported safety concerns were marine life $(47.4 \%)$ and cold/hypothermia (46.4\%), followed by boats (30.9\%), currents (19.6\%), cramps/fatigue (15.5\%), and other (14.4\%). A report of feeling more adversely affected by cold was associated with a lower BMI (Coef. $=-2.81 ; \mathrm{P}=0.002)$, lower $\%$ fat (Coef. $=-6.66 ; \mathrm{P}<0.001$ ), and less time in the water per swim (Coef. $=-4.23 ; \mathrm{P}=0.029)$, while a report of feeling less affected by cold was associated with a higher BMI (Coef. $=2.55 ; \mathrm{P}=0.001)$, higher $\%$ fat $($ Coef. $=3.83 ; \mathrm{P}=0.010)$, and more time in the water per swim (Coef. $=3.51 ; \mathrm{P}=0.039)$.

Conclusions: Individuals with a wide variety of ages, body types, and backgrounds are able to swim recreationally in cold water. Such swimmers typically are not obese and exceed the ACSM/AHA recommendations for weekly exercise. Marine life and cold/hypothermia are frequent safety concerns; our results suggest that swimmers who report worse cold tolerance are more likely to be leaner and limit time in the water, while those who report better cold tolerance are more likely to have a higher $\%$ body fat and spend more time in the water per swim.
\end{abstract}

Keywords: Swimming, body composition, exercise, physiology, hypothermia.

\section{INTRODUCTION}

The popularity of swimming in cold open water continues to increase [1-8]. Few large studies, however, have reported the detailed physical and other characteristics of cold-water swimmers, or examined the potential exercise benefits or safety concerns of recreational cold-water swimming.

*Address correspondence to this author at the 6 Locksley Avenue, \#8J North, San Francisco, CA 94122-3822, USA; Tel: 415-596-1685; Fax: 415-6811501; E-mail: nuckton@sutterhealth.org
In a prior work [5], we reported the detailed body composition variables of recreational cold-water swimmers. That study found that individuals with a wide range of body composition variables were able to swim regularly in cold water, and suggested that the $\%$ fat of cold-water swimmers was not elevated when compared to American averages.

In this current study, we further examine an expanded group of San Francisco Bay cold-water swimmers, with a focus on swimmer characteristics, exercise patterns, and swimmer perceptions of safety and cold tolerance. More 
specifically, swimmer exercise patterns are statistically compared to exercise recommendations from the American College of Sports Medicine/American Heart Association (ACSM/AHA) [9], and 3-month before-and-after comparisons of weight and other body habitus variables are presented in a subset of subjects. Swimmer safety concerns are also identified, and the relationships between swimmer perceptions of cold tolerance, body composition, and swim outcomes are analyzed.

\section{METHODS}

\section{Polar Bear Swim Event and Outcomes}

During the winter of 2010/2011, a total of 125 swimmers participated in the annual San Francisco Dolphin Club Polar Bear Swim. Swimmers participated in one of two categories. In general, swimmers were required to swim a minimum total of 40 cumulative miles $(64.4 \mathrm{~km})$ spread over a 3month period (December 21, 2010 - March 21, 2011), in the San Francisco Bay, without wetsuits or swim aids. However, individuals 60 years of age or older, could opt to participate either in the regular 40-mile $(64.4 \mathrm{~km})$ category, or in a special senior category, which required a minimum of only 20 cumulative miles $(32.2 \mathrm{~km})$ spread over the same 3month period.

The water temperature of the San Francisco Bay during the 3-month winter swim period ranged from $9.6^{\circ} \mathrm{C}\left(49.3{ }^{\circ} \mathrm{F}\right)$ to $12.6^{\circ} \mathrm{C}\left(54.7^{\circ} \mathrm{F}\right)$ [10]. Warm showers and saunas were available to all participants both before and after swimming. Although wetsuits were prohibited, insulating neoprene caps were permitted.

Participants could exceed the distance minimums, with honors going to those who accumulated the greatest number of miles. Swimmers swam at an individual pace and selfrecorded their mileage on a public recording chart. In a postevent survey, subjects were asked to report their average swim distance per day, average time in the water per swim, and average number of swim days per week. The average exercise time per week was calculated by multiplying the average time in the water per swim by the average number of swim days per week. The calculation of exercise time per week did not account for multiple swims in the same day (assumed only a single cold-water swim per day), and did not include other forms of exercise. The California Pacific Medical Center Institutional Review Board approved the study.

\section{Participants and Body Composition Measures}

Within 15 days of the completion of the Polar Bear Swim event, 103/125 total event swimmers (88 regular category swimmers (minimum 40 miles $(64.4 \mathrm{~km})$ ) and 15 senior category swimmers (minimum 20 miles $(32.2 \mathrm{~km})$ ) consented to height, weight, and circumference measurements, which were used to calculate body mass index (BMI) and \% body fat [5, 11-13]. BMI was calculated by dividing each subject's weight by his or her height in meters-squared $[5,11] . \%$ fat was estimated using a circumference-based technique $[5,12,13]$; utilizing this method, \% fat was calculated from height and circumference measurements of the neck and abdomen (at the level of the umbilicus) for men, and height and circumference measurements of the neck, waist (point of minimal abdominal circumference), and hips (largest horizontal circumference) for women. Measurements were made with a non-stretchable plastic tape measure, without compressing the skin and with the subject standing in a straight but nonrigid position. Details regarding the use of this circumference method can also be found in our prior work [5], which focused on the body composition of recreational cold-water swimmers, and included the majority of the subjects described in this current study.

All subjects underwent BMI and \% fat assessment within 15 days of completing the 3-month winter swim event. However, to allow for before-and-after comparisons, a subgroup of 50 subjects additionally consented to height, weight, and circumference measurements both before (within 15 days of the start) and again after (within 15 days of the finish) the 3-month winter swim period.

\section{Survey/Questionnaire}

Within 15 days of the finish of the 3-month winter swim period, subjects also responded to a questionnaire that included questions regarding their exercise patterns during the winter period, past swim experience, employment status, and perceptions of safety while swimming in open water. The survey also included a question that asked subjects to rate their tolerance to cold compared to other open-water swimmers who swam similar distances in similar water temperatures. Additional details pertaining to the questionnaire, including question wording, formation of composite variables, and response rates, can be found in the Appendix.

\section{Statistical Analysis}

For descriptive statistics, means \pm standard deviations and ranges are presented unless otherwise specified. The distance outcomes of the Polar Bear Swim event had clear minimum values of either 40 miles $(64.4 \mathrm{~km})$ (regular category) or 20 miles $(32.2 \mathrm{~km})$ (senior category), and the variable of total distance was not normally distributed. Estimated time in the water per swim and exercise time per week were also not normally distributed. Accordingly, nonparametric statistical tests were utilized as needed when examining these and other non-normally distributed variables.

One-sample median tests were used to compare the estimated exercise time per week of our swimmers to the ACSM/AHA recommendations [9]. The ACSM/AHA recommends a minimum of 60 minutes of vigorous-intensity exercise or 150 minutes of moderate-intensity exercise per week. Combinations of vigorous-intensity and moderateintensity exercise, (e.g., a total of 100 minutes/week), can also be done to meet the recommendation. Given the swimming conditions of the event, we assumed that the exercise intensity was intermediate, and compared the exercise times of our total subject group and regular category group (minimum 40 -mile $(64.4 \mathrm{~km})$ ) to a combination value of 100 minutes/week. For older swimmers, a higher overall exercise intensity was assumed, and we compared the exercise time of our senior category group (minimum 20 miles $(32.2 \mathrm{~km})$ ) to a combination value of 70 minutes/week. Spearman correlations were used to examine the relationships between age, total swim distance, exercise time per week, and other variables. 
In a subset of 50 swimmers who consented to measurements both prior to and after the 3-month swim period, paired t-tests were used for before-and-after comparisons of weight, BMI, and \% fat. Linear regression was used to examine the relationships between swimmer perceptions of their ability to endure cold water and body composition and exercise variables. All regression models included a variable to adjust for swimmers in the senior category who swam less than 40 miles. For regression models, a sensitivity analysis using log-transformed dependent variables was also done (see Appendix).

\section{RESULTS}

\section{Biophysical Characteristics}

Demographic data related to our subjects are summarized in Table 1. Table 1a summarizes the age, sex, and body composition of our total subjects $(\mathrm{N}=103)$, regular category subjects who completed the full 40 miles $(64.4 \mathrm{~km})$ within 3 months $(\mathrm{N}=88)$, and subjects in the senior category $(\mathrm{N}=15)$, who were only required to complete 20 miles $(32.2 \mathrm{~km})$ within 3 months. The average body mass index of the total subject group, and of subjects in both the regular and senior categories, was modestly elevated and in the overweight, but not obese category $[5,11,12]$. The average $\%$ fat values reported in this current study are consistent with those reported in prior studies of cold-water swimmers [3, 5], are within the broad accepted ranges for Americans, and in general do not reflect obesity $[11,12,14,15]$. Additional body composition results, including circumference data and stratification of $\%$ fat values for men and women, can be found in the Appendix.

\section{Swim Patterns and Comparison to ACSM/AHA Recommendations}

The swim patterns of the subjects, including the total distance achieved during the 3-month swim period, average swim distance per day, number of swim days per week, estimated time per swim, and estimated exercise time per week, are summarized in Table 1b. The number of swim days per week and time per swim were reported by 95 and 102 subjects respectively, allowing for the calculation of exercise time per week in 94 of 103 total subjects, 82 of 88 regular category subjects (minimum 40 miles $(64.4 \mathrm{~km})$ ), and 12 of 15 senior category subjects (minimum 20 miles $(32.2 \mathrm{~km}))$. Mean exercise times for the total group and each subgroup were as follows: total subject group (131.3 \pm 50.8 minutes/week); regular category subjects (136.8 \pm 50.8 minutes/week); senior category subjects $(93.9 \pm 32.6$ minutes/week).

The exercise times per week of our subjects are further summarized in Fig. (1). In the total group of subjects the median exercise time (120 minutes/week) was significantly greater than an intermediate ACSM/AHA combination value of 100 minutes/week (One-sample median test; $\mathrm{P}<0.001$ ). For subjects in the regular 40-mile $(64.4 \mathrm{~km})$ category, the

Table 1. Characteristics of San Francisco Cold-water Swimmers*

Table 1a. Age, Sex, and Biophysical Characteristics ${ }^{\dagger}$

\begin{tabular}{|c|c|c|c|c|c|}
\hline & Age (Yrs) \pm SD (Range) & Men N (\%) & Women N (\%) & BMI (kg/m $\mathbf{m}^{2} \pm$ SD (Range) & \% Fat \pm SD (Range) \\
\hline \hline Total Group N=103 & $54.3 \pm 10.8(24-79)$ & $76(73.8)$ & $27(26.2)$ & $25.9 \pm 3.6(19.0-39.1)$ & $23.8 \pm 7.5(6.9-51.9)$ \\
\hline Regular Category N=88 & $52.3 \pm 10.1(24-76)$ & $70(79.5)$ & $18(20.5)$ & $25.8 \pm 3.4(19.0-37.1)$ & $22.6 \pm 6.7(6.9-42.4)$ \\
\hline Senior Category N=15 & $66.5 \pm 5.9(61-79)$ & $6(40.0)$ & $9(60.0)$ & $26.6 \pm 4.7(20.6-39.1)$ & $31.0 \pm 8.2(21.4-51.9)$ \\
\hline
\end{tabular}

Table 1b. Swim Patterns and Exercise Time

\begin{tabular}{|c|c|c|c|c|c|}
\hline & $\begin{array}{c}\text { Total Distance } \\
(\mathbf{m i}(\mathbf{k m})) \pm \text { SD (Range) }\end{array}$ & $\begin{array}{c}\text { Swim Distance/Day } \\
(\mathbf{m i}(\mathbf{k m}) \mathbf{)} \pm \text { SD (Range) }\end{array}$ & $\begin{array}{c}\text { No. Swim Days/ } \\
\text { Week } \pm \text { SD (Range) }\end{array}$ & $\begin{array}{c}\text { Time/Swim } \\
(\text { Min) } \pm \text { SD (Range) }\end{array}$ & $\begin{array}{c}\text { Exercise Time/Week } \\
(\text { Min) } \pm \text { SD (Range) }\end{array}$ \\
\hline \hline Total Group N=103 & $\begin{array}{c}46.4 \pm 18.8(20-154) \\
(74.7 \pm 30.3(32.2-247.8))\end{array}$ & $\begin{array}{c}1.1 \pm 0.5(0.25-3.5) \\
(1.8 \pm 0.8(0.4-5.6))\end{array}$ & $4.2 \pm 1.2(2-7)$ & $31.6 \pm 8.2(17-60)$ & $131.3 \pm 50.8(51-315)$ \\
\hline Regular Category N=88 & $\begin{array}{c}50.3 \pm 17.6(40-154) \\
(81.0 \pm 28.3(64.4-247.8))\end{array}$ & $\begin{array}{c}1.1 \pm 0.5(0.5-3.5) \\
(1.8 \pm 0.8(0.8-5.6))\end{array}$ & $4.3 \pm 1.2(2-7)$ & $32.5 \pm 7.9(17-60)$ & $136.8 \pm 50.8(60-315)$ \\
\hline \multirow{2}{*}{ Senior Category N=15 } & $\begin{array}{c}23.9 \pm 4.4(20-34) \\
(38.5 \pm 7.1(32.2-54.7))\end{array}$ & $\begin{array}{c}0.6 \pm 0.2(0.25-1.0) \\
(1.0 \pm 0.3(0.4-1.6))\end{array}$ & $4.0 \pm 1.1(3-6)$ & $25.9 \pm 8.0(17-45)$ & $93.9 \pm 32.6(51-150)$ \\
\hline
\end{tabular}

Table 1c. Employment Characteristics ${ }^{\S}$

\begin{tabular}{|c|c|c|c|c|}
\hline & Full-Time Employment N (\%) & Part-Time Employment N (\%) & Unemployed N (\%) & Retired N (\%) \\
\hline \hline Total Group N=103 & $72(69.9)$ & $17(16.5)$ & $2(1.9)$ & $12(11.7)$ \\
\hline Regular Category N=88 & $68(77.3)$ & $11(12.5)$ & $2(2.3)$ & $7(8.0)$ \\
\hline Senior Category N=15 & $4(26.7)$ & $6(40.0)$ & $0(0)$ & $5(33.3)$ \\
\hline
\end{tabular}


Table 1d. Swimming Background"

\begin{tabular}{|c|c|c|c|c|}
\hline & $\begin{array}{c}\text { English Channel Soloist } \\
\text { N (\%) }\end{array}$ & $\begin{array}{c}\text { College/Other International/National } \\
\text { N (\%) }\end{array}$ & $\begin{array}{c}\text { High-School/Youth Aquatic } \\
\text { N (\%) }\end{array}$ & $\begin{array}{c}\text { Recreational Only } \\
\text { N (\%) }\end{array}$ \\
\hline \hline Total Group N=103 & $5(4.9)$ & $17(16.5)$ & $17(16.5)$ & $64(62.1)$ \\
\hline Regular Category N=88 & $4(4.5)$ & $16(18.2)$ & $17(19.3)$ & $51(58.0)$ \\
\hline Senior Category N=15 & $1(6.7)$ & $1(6.7)$ & $0(0)$ & $13(86.7)$ \\
\hline
\end{tabular}

*Results obtained after 3 months of swimming in cold open water. Total $\mathrm{N}=103$ swimmers. Regular category swimmers ( $\mathrm{N}=88$ ) were required to swim a minimum total of 40 cumulative miles $(64.4 \mathrm{~km})$ spread over a 3-month winter period, in the San Francisco Bay, without wetsuits or swim aids. Individuals 60 years of age or older, could opt to participate either in the regular 40-mile $(64.4 \mathrm{~km})$ category, or in a special senior category $(\mathrm{N}=15)$, which required a minimum of only 20 cumulative miles $(32.2 \mathrm{~km})$ spread over the same 3-month period (see text for further event description). Means \pm SD (range) or N(\%) shown.

${ }^{\dagger}$ All 103 subjects underwent post-event body composition assessment (see text for methods and Appendix for additional data and details).

${ }^{\ddagger}$ Total swim distance during the 3-month winter swim period was recorded by all 103 subjects. Swim distance per day was reported by 95 subjects. Number of swim days per week and time per swim were reported by 95 and 102 subjects respectively, allowing for the calculation of exercise time per week in 94 of 103 total subjects, 82 of 88 regular category subjects, and 12 of 15 senior category subjects.

${ }^{\S}$ Employment data from all 103 subjects. 4 categories created from more detailed survey responses of employment patterns and average work hours per week (see Appendix for survey question wording and details).

'Swimming background data from all 103 subjects. Categories created from open-ended responses (see Appendix for survey question wording and details). 3 swimmers reported that they had learned to swim as adults.

median exercise time (120 minutes/week) was also significantly greater than an intermediate combination value of 100 minutes/week (One- sample median test; $\mathrm{P}<0.001$ ). For subjects in the senior 20 -mile $(32.2 \mathrm{~km})$ category, the median exercise time (90 minutes/week) was lower but not significantly different than an intermediate combination value of 100 minutes/week $(\mathrm{P}=0.50)$, but was significantly greater than an intermediate combination value of 70 minutes/week (One- sample median test; $\mathrm{P}=0.041$ ).

As mentioned above, individuals 60 years of age or older could opt to participate in either the regular category or senior category. 42 of 103 subjects $(40.8 \%)$ in the total

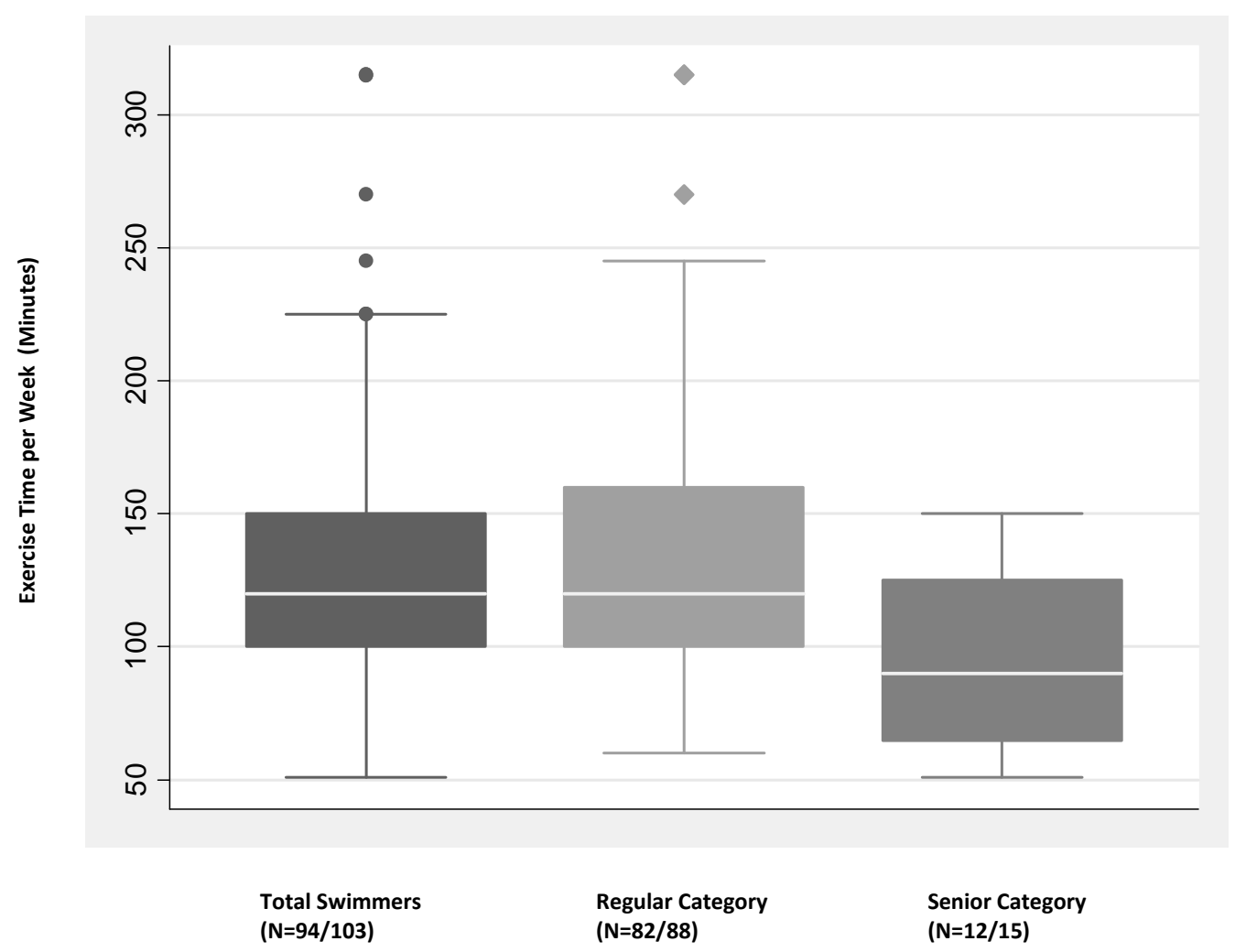

Fig. (1). Box Plot of Exercise Time per Week in San Francisco Cold-water Swimmers. Standard box plot in which the line in the middle of the box represents the median, the box extends from the $25^{\text {th }}$ percentile to the $75^{\text {th }}$ percentile (interquartile range), the whiskers extend to the upper and lower adjacent values (defined by a maximum of $1.5 \mathrm{X}$ the interquartile range), and points represent outliers. Based on available data, exercise time per week was calculated in 94 of 103 total subjects, 82 of 88 regular category subjects (minimum 40 miles (64.4 km)), and 12 of 15 senior category subjects (minimum 20 miles $(32.2 \mathrm{~km})$ ). Median exercise time in both the total group (120 minutes/week) and the regular category group (also 120 minutes/week) was statistically greater than an intermediate ACSM/AHA combination value of 100 minutes/week ( $\mathrm{P}<0.001$ for both comparisons); median exercise time in the senior group ( 90 minutes/week) was statistically greater than an intermediate ACSM/AHA combination value of 70 minutes/week $(\mathrm{P}=0.041)$. 
group, and 27 of 88 subjects $(30.7 \%)$ in the regular category were 60 years of age or older; by definition, all 15 subjects in the senior category were 60 years of age or older. Remarkably, the oldest subject in the regular category (age 76 years) finished second overall in total distance achieved $(117$ miles $(188.3 \mathrm{~km})$ ) and was tied with another subject for the longest average exercise time per week (315 minutes/week).

There was a highly significant correlation between exercise time per week and total swim distance achieved during the 3-month winter period in the total subject group (Spearman; $\mathrm{r}=0.55 ; \mathrm{P}<0.001$ ) and in regular category subjects (Spearman; $\mathrm{r}=0.52 ; \mathrm{P}<0.001$ ); this trend was not detected in our much smaller sample of senior category subjects $(\mathrm{P}=0.81)$. There was no significant correlation between age and total distance achieved in either regular category subjects $(\mathrm{P}=0.78)$ or senior category subjects $(\mathrm{P}=0.29)$. There were also no significant correlations between exercise time per week and age in either the total subject group $(\mathrm{P}=0.48)$, regular category subjects $(\mathrm{P}=0.59)$, or senior category subjects $(\mathrm{P}=0.35)$.

\section{Employment Characteristics}

Employment is summarized in Table 1c. The majority of subjects were employed full-time. As expected, a higher percentage of subjects in the senior category were retired when compared to the regular category subjects.

\section{Swimming Background and Experience}

A wide variety of swimming backgrounds was reported (Table 1d). In the group overall, 5 subjects had successfully completed a solo English Channel crossing. However, in all groups, the majority of subjects were in a recreational only category. Interestingly, 3 subjects reported that they had not learned to swim until they were adults.

Although most swam on a recreational level, the majority of our subjects had prior winter swimming experience and had participated in prior Polar Bear Swim events, which occur annually. The average number of prior annual Polar Bear Swims for the total group (91/103 subjects responded clearly to the survey question, which made no distinction between the regular or senior category) was $7.8 \pm 8.8$ swims; thus on average our subjects had almost 8 years of prior winter swimming experience. 16 respondents were first-time Polar Bear swimmers. Remarkably, one subject had completed 33 prior Polar Bear Swims, each by definition in a separate winter.

\section{Before-and-After Comparisons of Body Composition}

50 subjects consented to biophysical measurements both before and after the 3-month swim period. Overall, 27 subjects lost weight (mean weight loss: $2.1 \pm 2.6 \mathrm{~kg}$; range of weight loss: $0.1-10.8 \mathrm{~kg}$ ) and 23 subjects gained weight (mean weight gain: $1.2 \pm 0.9 \mathrm{~kg}$; range of weight gain: 0.1 $2.9 \mathrm{~kg}$ ). For the group overall, there were no significant before-and-after differences in any body composition parameter by paired statistical testing (results for total subgroup of 50 subjects shown in Table 2). Before-and-after comparisons remained non-significant $(\mathrm{P}>0.09)$ in all additional subgroups: regular category, senior category, men only, women only (data not shown). Thus, while an individual swimmer may have gained or lost weight, our subjects overall did not statistically gain or lose weight, or change BMI or $\%$ fat, during the 3 -month period.

\section{Safety Concerns and Perceptions of Cold Tolerance}

No subject was seriously injured while participating in the Polar Bear Swim event we describe. While is it possible that swimmers in our study experienced mild hypothermia or minor injuries, body temperature and minor injury prevalence were not specifically tracked. All of the safety data in this study reflect reported concerns and not actual injuries; additional information regarding the survey question wording can be found in the Appendix.

Reported safety concerns for all survey respondents (97 respondents) are summarized in Fig. (2). 82.5\% percent (80 of a total of 97 respondents) reported that they had felt concerned for their safety while swimming in the San Francisco Bay. Marine life ( $\mathrm{N}=46 ; 47.4 \%$ of respondents) and cold/hypothermia ( $\mathrm{N}=45 ; 46.4 \%$ of respondents) were the most commonly identified safety concerns, followed by boats $(\mathrm{N}=30 ; 30.9 \%$ of respondents), currents $(\mathrm{N}=19 ; 19.6 \%$ of respondents), cramps ( $\mathrm{N}=15 ; 15.5 \%$ of respondents $)$, and other $(\mathrm{N}=14 ; 14.4 \%$ of respondents). Examples of other safety concerns specified by respondents were varied and included collision with other swimmers, pollution, piloting errors, and fog/visibility.

A total of 97 subjects responded to the survey question regarding cold tolerance. Compared to other swimmers who swam similar distances in water of similar temperatures, 22 respondents $(22.7 \%)$ reported that they were affected more/became colder, 33 respondents $(34.0 \%)$ reported that they were affected less/stayed warmer, and 42 respondents $(43.3 \%)$ reported that they had no differences in cold tolerance (see Appendix for survey question wording). By linear regression, a swimmer who reported being more affected by cold was likely to have had a BMI $2.81 \mathrm{~kg} / \mathrm{m}^{2}$ lower (Coef. $\left.=-2.81 ; \mathrm{P}=0.002\right)$, $\%$ fat $6.66 \%$ lower (Coef. $=-6.66 ; \mathrm{P}<0.001$ ), and 4.23 minutes less time in the water per swim (Coef. $=-4.23 ; \mathrm{P}=0.029)$, than a swimmer in the same distance category (regular or senior) who

Table 2. Before-and-After Comparisons in a Subset of 50 Swimmers*

\begin{tabular}{|c|c|c|c|c|}
\hline & Pre-Event (Mean) & Post-Event (Mean) & Change (Mean \pm SD (Range)) $^{\text {P-Value }^{\dagger}}$ \\
\hline \hline Weight $(\mathrm{kg})$ & 78.8 & 78.2 & $-0.5 \pm 2.6(-10.8$ to 2.9$)$ & 0.15 \\
\hline BMI $\left(\mathrm{kg} / \mathrm{m}^{2}\right)$ & 25.8 & 25.6 & $-0.2 \pm 0.9(-3.8$ to 1.1$)$ & 0.14 \\
\hline$\%$ Fat & 23.8 & 23.5 & $-0.3 \pm 2.0(-6.8$ to 4.4$)$ & 0.29 \\
\hline
\end{tabular}

*Variables measured before and after 3 months of winter swimming (see text for event description). A total of 50 swimmers underwent before-and-after measurements ( 37 men, 13 women, age: $56.0 \pm 7.7$ yrs, BMI: $25.6 \pm 2.9 \mathrm{~kg} / \mathrm{m}^{2}, \%$ fat: $23.5 \pm 7.6$, total swim distance achieved: $48.0 \pm 21.0$ miles, 44 regular category and 6 senior category); Before-and-after comparisons remained non-significant $(\mathrm{P}>0.09)$ in all additional subgroups: regular category, senior category, men only, women only (data not shown).

${ }^{\dagger}$ Paired t-test used for all comparisons. 


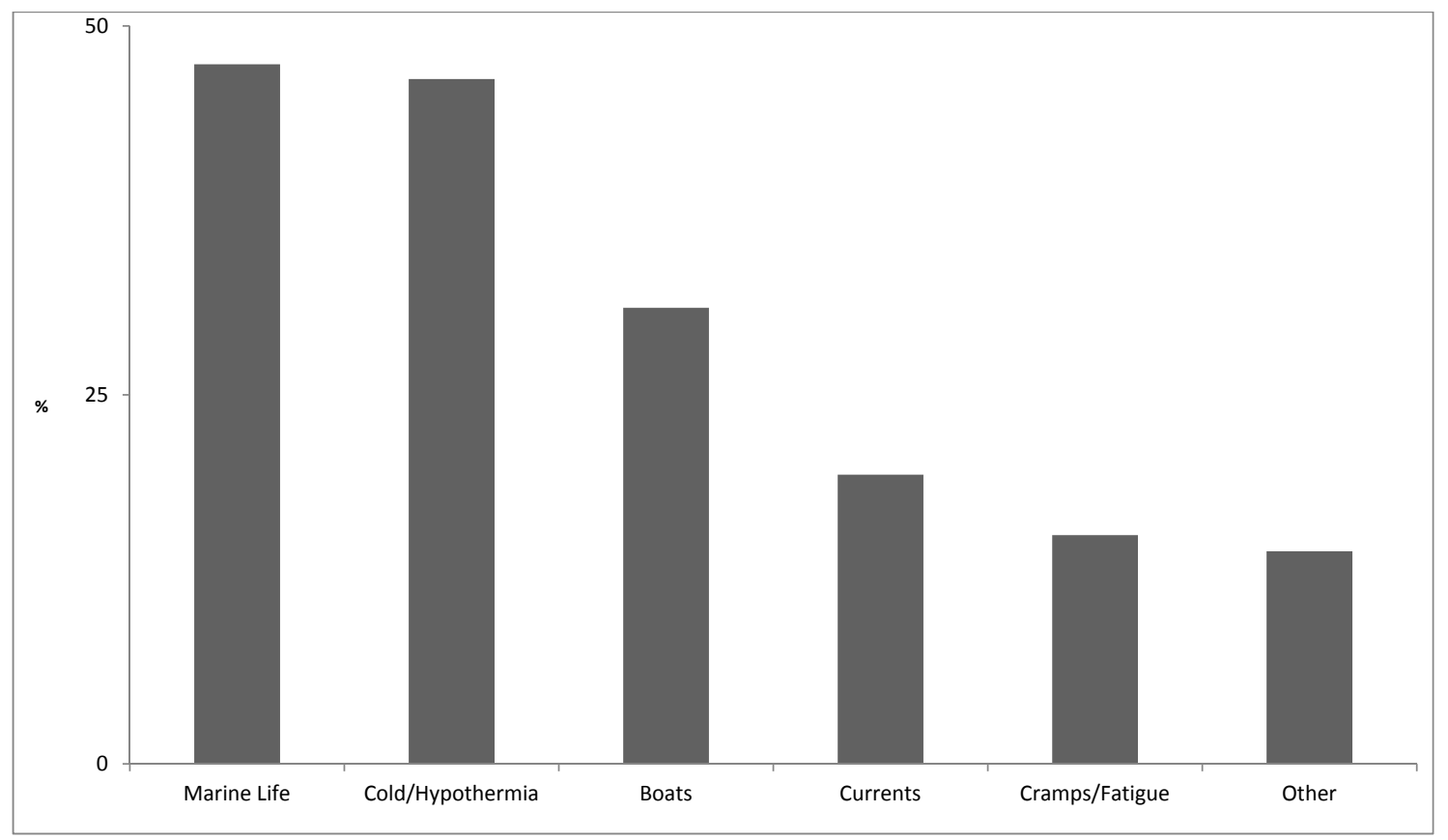

Fig. (2). Safety Concerns of San Francisco Cold-water Swimmers. Category of safety concern on x-axis; \% of responses on y-axis. A total of 97 swimmers responded to survey questions pertaining to safety (see Appendix for exact survey question wording and details). Respondents were not asked to prioritize and could choose more than one safety concern. Examples of other concerns offered by respondents included: collision with other swimmers, pollution, piloting errors, and fog/visibility.

reported either normal or better cold tolerance. A swimmer who reported feeling less affected by cold was likely to have had a BMI $2.55 \mathrm{~kg} / \mathrm{m}^{2}$ higher (Coef. $=2.55 ; \mathrm{P}=0.001$ ), $\%$ fat $3.83 \%$ higher (Coef. $=3.83 ; \mathrm{P}=0.010)$, and 3.51 minutes more time in the water per swim (Coef. $=3.51 ; \mathrm{P}=0.039)$, than a swimmer in the same distance category (regular or senior) who reported either normal or worse cold tolerance (Table 3).

Total swim distance, exercise time per week, age, and sex were not associated with perceptions of cold tolerance (either better or worse) in any regression model $(\mathrm{P}>0.1)$. For regression models, a sensitivity analysis using log-trans- formed dependent variables yielded similar conclusions (see Appendix for details and additional results).

\section{DISCUSSION}

Our data suggest that individuals with a wide variety of ages and backgrounds swim recreationally in cold water. A typical subject in our study was in a middle-aged category and employed full-time. While 5 subjects had previously completed solo English Channel swims, the majority of our subjects had only a recreational swimming background, and 3 swimmers reported that they had learned to swim as adults. Age was not an apparent barrier to swimming; over $40 \%$ of

Table 3. Linear Regression of Cold Tolerance Perception, Body Mass Index, \% Fat, and Time in the Water Per Swim ${ }^{*}$

\begin{tabular}{|c|c|c|c|}
\hline \multirow{2}{*}{} & & \multicolumn{2}{|c|}{ Independent Variable $^{\dagger}$} \\
\cline { 2 - 4 } & & Endure Cold Worse & Endure Cold Better \\
\hline \hline \multirow{2}{*}{} & $\mathrm{BMI}\left(\mathrm{kg} / \mathrm{m}^{2}\right)$ & Coef. $=-2.81 ; \mathrm{P}=0.002$ & Coef. $=2.55 ; \mathrm{P}=0.001$ \\
\cline { 2 - 4 } & $\%$ Fat & Coef. $=-6.66 ; \mathrm{P}<0.001$ & Coef. $=3.83 ; \mathrm{P}=0.010$ \\
\cline { 2 - 4 } & Time $/$ Swim $(\mathrm{min})$ & Coef. $=-4.23 ; \mathrm{P}=0.029$ & Coef. $=3.51 ; \mathrm{P}=0.039$ \\
\hline
\end{tabular}

*Linear regression done separately for each dependent variable (either body mass index (BMI), or \% body fat ( \% Fat), or time in the water per swim (Time/Swim)) with each independent variable (either Endure Cold Worse, or Endure Cold Better). A variable to adjust for swimmers in the senior category who swam less than 40 miles was utilized in all regression models. Each coefficient is thus from a single multivariable regression done with: 1. a single dependent variable (either BMI, or \% Fat, or Time/Swim) and 2. a single independent variable (either Endure Cold Worse or Endure Cold Better), and 3. the adjustment variable for the senior category. See Appendix for adjusted $\mathrm{R}^{2}$ values and sensitivity analysis using log-transformed dependent variables.

${ }^{\dagger}$ A total of 97 subjects responded to the survey question regarding cold tolerance. Compared to other swimmers in the Polar Bear event, 22 respondents reported that they were affected more/became colder, 33 respondents reported that they were affected less/stayed warmer, and 42 respondents reported that they had no differences in cold tolerance (see Appendix for exact question wording).

${ }^{\ddagger}$ Other variables (total swim distance, exercise time per week, age, and sex), were not significantly associated with perceptions of cold tolerance (either better or worse) in any regression model $(\mathrm{P}>0.1)$. 
subjects were 60 years of age or older. Clearly, our subjects appeared to be from a robust and varied demographic, and in general were not professional or elite athletes.

The results from our prior study [5] more specifically suggested that recreational cold-water swimmers did not have an increased \% body fat when compared to healthy average Americans. Although our current study included only 15 additional subjects, the average BMI and \% fat values were again found to be grossly similar to average American values and did not reflect obesity $[11,12,14,15]$. Thus, our swimmers in general did not appear to be out of the ordinary based on either demographic or physical data.

It can be safely assumed that swimmers in our study were highly motivated individuals. With a high degree of statistical significance, our subjects appeared to exceed the ACSM/AHA recommendations [9] for minimum weekly exercise. These results suggest that swimmers were healthconscious and that recreational cold-water swimming is more than a novelty activity.

Overall, the swimmers in our study who had before-andafter comparisons did not appear statistically to either gain or lose weight, or change BMI or \% fat, despite swimming consistently in cold water throughout the winter months. Similarly, in other studies, pool swimming did not yield weight loss when other forms of exercise did [16, 17]. Furthermore, in an additional prior study, subjects had an increased caloric intake after swims in cold water compared to swims in warm water [18]. Thus, from prior studies and our new data, some might conclude that swimming in cold water is not conducive to weight loss.

On the other hand, several individuals in our study did lose substantial amounts of weight. While it is tempting to speculate that cold-water swimming contributed to weightloss in some individuals, we do not have detailed data regarding weight-loss goals, diet, chronic disease, or acute illnesses during the study period. Thus, we can draw no firm conclusions about the relationship between cold-water swimming and weight regulation. However, our current results do suggest, that cold-water swimming is an activity that enables participants to meet or exceed the ACSM/AHA exercise recommendations, and by extension could contribute to calorie-burning and overall health maintenance.

Yet despite the potential health benefits, any open-water swimming activity is associated with risk. One of the more frequent safety concerns reported by our swimmers was cold/hypothermia, which has been identified as a risk associated with open-water swimming in prior studies [1-3].

As discussed in our previous study [5], our subjects were likely acclimatized from repeated immersion in cold water, and thus likely had a limited swim performance advantage. However, prior studies have suggested that the key determinants of core cooling are biophysical parameters such as increased size and total $\%$ fat $[1-5,19-24]$, rather than acclimatization $[5,19,24]$. Our swimmers had body size and $\%$ fat values that were grossly similar to average American values. Thus, based on several prior studies, they would not be expected to have had better direct physical protection from true core hypothermia, even if they were acclimatized.
Conversely, newer studies have suggested that repeated cold exposure could cause an increase in levels or activity of thermogenic brown fat [25-29], which might improve core temperature regulation and body heat production, even without an increase in overall $\%$ fat or body size. Measurement of brown fat requires sophisticated technology and was beyond the scope of our study.

While it is theoretically possible that swimming in cold water could cause an increase in brown fat levels or activity, to date brown fat has never been measured in a large group of dedicated cold-water swimmers. Thus, further study will be needed to determine if swimming regularly in cold water contributes to substantial increases in brown fat, and whether such increases contribute to meaningful and consistent improvements in core temperature.

Prior studies have suggested that leaner swimmers voluntarily limit time in cold water $[1,5]$. In our current study, we approached a similar question from a somewhat different direction. We asked swimmers to subjectively rate their perception of cold tolerance, and then examined the relationship of that response to BMI, $\%$ fat, and time in the water per swim. Interestingly, those who reported worse cold tolerance were more likely to have been leaner and to have spent less time in the water per swim, and those who reported better cold tolerance were more likely to have had a higher $\%$ fat and to have spent more time in the water per swim. These results suggest that experienced swimmers may be able to gauge, at least partially, their ability to swim in and endure cold water.

Cold and hypothermia were not the only safety concerns reported by our swimmers. Marine life, in fact, was identified with a slightly higher frequency than cold/hypothermia. While many might assume that sharks were a primary concern, shark attacks within the San Francisco Bay are virtually non-existent; although shark attacks do occur infrequently in the Pacific Ocean waters outside of the Bay, no shark attack has been reported within the San Francisco Bay in more than 80 years [30]. In contrast, pinniped (seals and sea lions) bites and attacks are occasionally reported by swimmers [31], and the marine life safety concern expressed by our subjects most likely reflects this possibility.

Older swimmers in our study deserve further mention. Remarkably, over $40 \%$ of our total group was 60 years of age or older, and although they had an option to swim in a less rigorous senior category, over $30 \%$ of regular category swimmers were 60 years of age or older. Although some might assume that younger individuals would swim longer and farther, this was not clearly the case; in the regular category, which included swimmers of all ages, we found no correlation either between age and total swim distance or between age and exercise time per week. Furthermore, the swimmer who placed second overall in total distance achieved during the winter, (and who was tied with another swimmer for the longest average exercise time per week), was 76 years of age.

Despite the large number of rigorous older swimmers, our study yields no conclusions about cold-water swimming and longevity. Prior work has suggested a wide variety of possible health benefits related to swimming in cold water [32-39], 
including improved immune response [34, 35], beneficial hormonal changes including insulin modulation and improved glucose regulation [36], antioxidative protection [37, 38], improvements in general well-being and energy levels [39], and symptomatic relief in patients with medical conditions such as asthma and fibromyalgia [39]. We did not study any of these outcomes or parameters, and we are cautious about attributing health advantages to cold-water swimming beyond the exercise benefits we discuss above.

Nonetheless, cold-water swimming appears to be an inclusive exercise activity that can be enjoyed by both older and younger swimmers. Perhaps few other outdoor activities have attracted such a diverse population, with relatively few apparent limits in age, body size, or athletic background. The lack of limits suggests that cold-water swimming will continue to increase in popularity, and that the sport could have benefits for older, obese, or previously sedentary individuals.

Our study utilized a first-time, non-validated questionnaire, and composite variables were created prior to analysis. The circumference-based method [12, 13] we used to estimate $\%$ fat is less commonly used in research, may be less accurate than other methods, and is a further potential study limitation. The method was originally developed using a younger population [13] and has not been specifically validated in older adults. Because of the changes in body composition that occur with aging, body fat could have been higher in our older subjects at circumferences that were similar to those of the original younger study population [13] and $\%$ fat may have been underestimated.

This study focused on a general and recreational population that had access to warm showers and saunas, and not on elite athletes or more extreme conditions [40-42], and results should be interpreted accordingly. Subjects were not tracked past the 3month swim period; further longitudinal tracking may better define swimmer motivation and the overall health implications of swimming regularly in cold water.

\section{CONCLUSION}

Individuals with a wide variety of ages, body types, and backgrounds are able to swim recreationally in cold water. Such swimmers typically are not obese and exceed the ACSM/AHA recommendations for minimum weekly exercise. Cold-water swimming thus appears to be a healthy activity that can be enjoyed both by younger and older adults. Marine life and cold/hypothermia are frequent safety concerns; our results suggest that swimmers who report worse cold tolerance are more likely to be leaner and limit time in the water, while those who report better cold tolerance are more likely to have a higher $\%$ body fat and spend more time in the water per swim.

\section{CONFLICT OF INTEREST}

No author has a financial conflict of interest. Thomas $J$. Nuckton and Steven P. Schatz were subjects in this study.

\section{ACKNOWLEDGEMENTS}

The authors gratefully acknowledge the San Francisco Dolphin Swimming and Boating Club for general nonfinancial support, and JD Durst, Phyllis J. Hunt, Thomas V. Hunt, Michael A. Kohn, Thomas D. McCall, Ryan C. Murphy, John G. Nuckton, and Connie J. Wellen, for technical assistance, statistical advice, manuscript review, and data acquisition.

\section{APPENDIX}

\section{Survey/Questionnaire}

\section{Question Wording and Composite Variables}

\section{Employment}

Which BEST describes your situation during the period, December 21, 2010 - March 21, 2011 (circle):

\section{a. retired}

b. not working and not seeking employment (e.g., on sabbatical, a break from work etc.)

c. unemployed and looking for employment

d. employed full-time

e. employed part-time

f. full-time student

g. part-time student

h. combination student/employed

i. currently disabled

j. full-time homemaker

k. combination homemaker/employed

On average, how many hours a week did you spend in paid employment?

Based on the results of the above two questions, 4 categories were created: 1. Full-time employment, 2. Part-time employment, 3. Unemployed, 4. Retired.

\section{Cold Tolerance}

Compared to other Dolphin Club members who swim similar distances in water of similar temperatures, please choose the category that best applies to your ability to endure cold water:
a. I am affected more/become colder
b. affected less/stay warmer
c. no differences

\section{Swim Experience}

Briefly outline your prior swimming experience (for example: competitive swimming experience - high school, college; recreational only; English Channel Swims; others etc.):

From this open question, 4 categories were created: 1. English Channel Soloist, 2. College/Other International/ National, 3. High-school/Youth Aquatic, 4. Recreational Only.

\section{Safety Concerns}

Have you ever been concerned for your safety while swimming in the San Francisco Bay?

\section{a. Yes \\ b. No}

If you have been concerned for your safety, which of the following concerned you (circle all that apply):
a. cold/hypothermia
b. current
c. cramps/fatigue
d. marine life (sharks; sea lions, seals, jellyfish, etc.)
e. boats/shipping
f. other (please specify): 


\section{Additional Survey Questions and Response Rates}

Subjects were also asked to quantify, by providing a single value, average swim distance per day, average number of swim days per week, and the number of prior Polar Bear swims in which they had participated. A question regarding average time per swim was not included on the initial questionnaire. However, 102/103 subjects subsequently provided this information directly, either verbally or by email. Average exercise time per week was calculated as outlined in the Methods section of the text.

In general, 97/103 subjects completed the questionnaire, a subject response rate of $94.2 \%$. For the variables of employment characteristics and swimming background, 6 subjects who had not completed the questionnaire subsequently provided information directly, allowing for complete reporting of these variables in all 103 subjects. Additional details pertaining to the response rates of specific questions can be found throughout the Results section of the text and in the table and figure legends.

\section{Additional Body Composition Data (Stratification of Men vs Women and Circumference Data)}

Total Sample: $\mathrm{N}=103$

Men $(\mathrm{N}=76)$

Weight (kg): 84.6 $\pm 14.2(53.4-148.0)$

Height (cm): $178.6 \pm 8.1(158.4-205.4)$

BMI $\left(\mathrm{kg} / \mathrm{m}^{2}\right): 26.4 \pm 3.3(20.7-37.1)$

\%Fat: $21.2 \pm 5.6(6.9-34.6)$

Neck (cm): $41.1 \pm 2.5(35.6-50.8)$

Abdomen (cm): $95.1 \pm 9.9$ (68.6 -121.9)

Women $(\mathrm{N}=27)$

Weight (kg): $69.7 \pm 12.4$ (47.6-103.4)

Height (cm): $168.3 \pm 7.0(146.6-179.5)$

BMI $\left(\mathrm{kg} / \mathrm{m}^{2}\right): 24.6 \pm 4.2(19.0-39.1)$

\%Fat: $31.2 \pm 7.4(20.0-51.9)$

Neck (cm): $35.0 \pm 2.4(30.5-41.9)$

Waist $(\mathrm{cm}): 81.0 \pm 9.9(66.0-109.2)$

Hip (cm): $101.5 \pm 8.6(87.6-120.7)$

Details pertaining to the body composition of the majority of swimmers in this study can also be found in our prior work [5].

Linear-Regression Sensitivity Analysis Using Both Unaltered (A) and Log-transformed (B) Dependent Variables

A.

\begin{tabular}{|c|c|c|c|}
\hline & & \multicolumn{2}{|c|}{ Independent Variable } \\
\hline & & Endure Cold Worse & Endure Cold Better \\
\hline \multirow{3}{*}{ 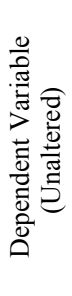 } & $\begin{array}{c}\mathrm{BMI} \\
\left(\mathrm{kg} / \mathrm{m}^{2}\right)\end{array}$ & $\begin{array}{c}\text { Coef. }=-2.81 ; \\
\mathrm{P}=0.002 \mathrm{R}^{2}(\operatorname{adj})=0.08\end{array}$ & $\begin{array}{c}\text { Coef. }=2.55 \\
\mathrm{P}=0.001 \mathrm{R}^{2}(\operatorname{adj})=0.09\end{array}$ \\
\hline & $\begin{array}{l}\% \\
\text { Fat }\end{array}$ & $\begin{array}{c}\text { Coef. }=-6.66 ; \\
\mathrm{P}<0.001 \mathrm{R}^{2}(\operatorname{adj})=0.29\end{array}$ & $\begin{array}{c}\text { Coef. }=3.83 \\
\mathrm{P}=0.010 \mathrm{R}^{2}(\operatorname{adj})=0.21\end{array}$ \\
\hline & $\begin{array}{l}\text { Time/Swim } \\
\text { (min) }\end{array}$ & $\begin{array}{c}\text { Coef. }=-4.23 ; \\
\mathrm{P}=0.029 \mathrm{R}^{2}(\mathrm{adj})=0.14\end{array}$ & $\begin{array}{c}\text { Coef. }=3.51 ; \\
\mathrm{P}=0.039 \mathrm{R}^{2}(\mathrm{adj})=0.13\end{array}$ \\
\hline
\end{tabular}

B.

\begin{tabular}{|c|c|c|c|}
\hline & & \multicolumn{2}{|c|}{ Independent Variable } \\
\hline & & Endure Cold Worse & Endure Cold Better \\
\hline \multirow{3}{*}{ 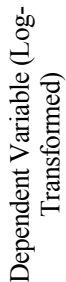 } & $\begin{array}{l}\ln (\mathrm{BMI}) \\
\left(\mathrm{kg} / \mathrm{m}^{2}\right)\end{array}$ & $\begin{array}{c}\text { Coef. }=-0.11 ; \\
\mathrm{P}=0.001 \mathrm{R}^{2}(\mathrm{adj})=0.09\end{array}$ & $\begin{array}{c}\text { Coef. }=0.09 ; \\
\mathrm{P}=0.002 \mathrm{R}^{2}(\text { adj })=0.08\end{array}$ \\
\hline & $\begin{array}{c}\text { Ln } \\
(\% \text { Fat })\end{array}$ & $\begin{array}{c}\text { Coef. }=-0.32 ; \\
\mathrm{P}<0.001 \mathrm{R}^{2}(\mathrm{adj})=0.27\end{array}$ & $\begin{array}{c}\text { Coef. }=0.15 ; \\
\mathrm{P}=0.027 \mathrm{R}^{2}(\operatorname{adj})=0.16\end{array}$ \\
\hline & $\begin{array}{c}\ln (\text { Time/Swim }) \\
(\text { min })\end{array}$ & $\begin{array}{c}\text { Coef. }=-0.13 ; \\
\mathrm{P}=0.025 \mathrm{R}^{2}(\mathrm{adj})=0.17\end{array}$ & $\begin{array}{c}\text { Coef. }=0.09 ; \\
\mathrm{P}=0.092 \mathrm{R}^{2}(\operatorname{adj})=0.15\end{array}$ \\
\hline
\end{tabular}

Linear regression done as outlined in text and Table $\mathbf{3}$ and repeated with substitution of log-transformed dependent variables.

BMI and time/swim were not normally distributed, and regression diagnostics of some models indicated non-linear associations. However, because we found similar patterns using the less-interpretable log-transformed variables, and because our goal was to summarize the association between perceived cold tolerance and the dependent variables (and not precise prediction of the dependent variables), we opted to retain unaltered variables in the models presented in the text.

The relatively small $\mathrm{R}^{2}$ values and significant $\mathrm{p}$-values suggest that the independent variables account for a small percent of the variation of the dependent variables, and the models thus reflect a generally reliable but less exact predictive relationship. For example, swimmers who reported that they endured cold worse were likely to have had a lower BMI with a high level of statistical significance. However, because many factors affect BMI, including caloric intake, genetics, and other variables, the model would not be expected to predict a swimmer's actual BMI with a high level of accuracy simply based on a report of worse cold tolerance. Similar results were found for $\%$ fat and time/swim. An opposite and consistent pattern was found for swimmers who reported that they endured cold better.

Analysis of swim distance per day (which was not normally distributed) yielded inconsistent results. There was an association between swim distance per day (without logtransformation) and endure cold worse (Coef. $=0.22$, $\left.\mathrm{P}=0.043, \mathrm{R}^{2}(\operatorname{adj})=0.17\right)$, but no association between swim distance per day and endure cold better $(\mathrm{P}=0.83)$. Following log-transformation of swim distance per day, no significant associations were found $(\mathrm{P}>0.1$ for both endure cold worse and endure cold better).

\section{REFERENCES}

[1] Keatinge WR, Khartchenko M, Lando N, Lioutov V. Hypothermia during sports swimming in water below $11^{\circ} \mathrm{C}$. Br J Sports Med 2001; 35: 352-3.

[2] Brannigan D, Rogers IR, Jacobs I, Montgomery A, Williams A, Khangure N. Hypothermia is a significant medical risk of mass participation long-distance open water swimming. Wilderness Environ Med 2009; 20: 14-8.

[3] Nuckton TJ, Claman DM, Goldreich D, Wendt FC, Nuckton JG. Hypothermia and afterdrop following open water swimming: the Alcatraz/San Francisco swim study. Am J Emerg Med 2000; 18: 703-7.

[4] Loupos D, Tsalis G, Papadopoulos A, Mathas G, Mougios V. Physiological and biochemical responses to competitive swimming in cold water. Open Sports Med J 2008; 2: 34-7. 
[5] Nuckton TJ, Kohn MA. Body composition of cold-water swimmers: the San Francisco polar bear swim study. Open Sports Med J 2012; 6: 48-51.

[6] Sward S. Sunday routine: Lou Marcelli. Sunrise to sunset on the wharf. New York Times January 9, 2010. Available online at: http://www.nytimes.com/2010/01/10/us/10sfroutine.html?_r=0

[7] Whiting S. Frigid water swimmer seeks to tie a record. San Francisco Chronicle March 11, 2013. Available online at: http://www.sfgate.com/ living/article/Frigid-water-swimmer-seeks-to-tie-a-record-4345315.php

[8] Bondurant M. Dangerous when wet - learning to survive open water swimming (online title). Outside Magazine July, 2013. Available online (June 11, 2013) at: http://www.outsideonline.com/outdoor-adventure/w ater-activities/swimming/Give-Us-Your-Tired-Your-Sore-Your-Shrivel ed-Masses.html

[9] Haskell WL, Lee M, Russell R, et al. Physical activity and public health; updated recommendation for adults from the American College of Sports Medicine and the American Heart Association. Circulation 2007; 116: 1081-93.

[10] National Oceanic and Atmospheric Administration (NOAA). National Oceanic and Atmospheric Administration's National Data Buoy Center. Station FTPC1-9414290-San Francisco, CA. Historical data and climatic summaries; standard meteorological data: 2010, 2011. Available online at: http://www.ndbc.noaa.gov/station_history.php?stat ion $=\mathrm{ftpc} 1$

[11] American College of Sports Medicine. The American College of Sports Medicine's Guidelines for Exercise Testing and Prescription. $8^{\text {th }}$ ed. Baltimore, MD: Williams \& Wilkins 2010.

[12] United States Department of Defense. DoD physical fitness and body fat programs and procedures. DoD Instruction 1308.3. United States Department of Defense; November 5, 2002. Available online at: http://www.dtic.mil/whs/directives/corres/pdf/130803p.pdf

[13] Hodgdon J, Beckett M. Prediction of percent body fat for U.S. Navy men and women from body circumferences and height. Reports No. 8429 and 84-11. San Diego, CA: Naval Health Research Center 1984.

[14] McDowell MA, Fryar CD, Ogden CL, Flegal KM. Athropometric reference data for children and adults: United States, 2003-2006. National Health Statistics Reports Number 10; October 22, 2008. Available online at: http://www.cdc.gov/nchs/data/nhsr/nhsr010.pdf.

[15] Gallagher D, Heymsfield SB, Heo M, Jebb SA, Murgatroyd PR, Sakamoto Y. Healthy percentage body fat ranges: an approach for developing guidelines based on body mass index. Am J Clin Nutr 2000; 72: 694-701.

[16] Gwinup G. Weight loss without dietary restriction: efficacy of different forms of aerobic exercise. Am J Sports Med 1987; 15: 275-9.

[17] Tanaka H, Bassett DR, Howley ET. Effects of swim training on body weight, carbohydrate metabolism, lipid and lipoprotein profile. Clin Physiol 1997; 17: 347-59.

[18] White LJ, Dressendorfer RH, Holland E, McCoy SC, Ferguson MA. Increased caloric intake soon after exercise in cold water. Int J Sports Nutr Exerc Metab 2005; 15: 38-47.

[19] Steinman AM, Hayward JS. Cold Water Immersion. In: Paul S. Auerbach Ed. Wilderness medicine, management of wilderness and environmental emergencies. $3^{\text {rd }}$ ed. St. Louis, MO: Mosby-Year Book, Inc. 1995; pp. 104-28.

[20] Golden F, Tipton M. Essentials of Sea Survival. Champaign, IL: Human Kinetics 2002.

[21] Tarlochan F, Ramesh S. Heat transfer model for predicting survival time in cold water immersion. Biomed Eng Appl Basis Commun 2005; 17: $159-66$
[22] Nuckton TJ, Goldreich G, Rogaski KD, Lessani TM, Higgins PJ, Claman DM. Hypothermia from prolonged immersion: biophysical parameters of a survivor. J Emerg Med 2002; 22: 371-4.

[23] Xu X, Turner CA, Santee WR. Survival time prediction in marine environments. J Therm Biol 2011; 36: 340-5.

[24] Cappaert TA, Stone JA, Castellani JW, Krause BA, Smith D, Stephens BA. National Athletic Trainer's Association position statement: environmental cold injuries. J Athl Training 2008; 43: 640-58.

[25] van Marken Lichtenbelt WD, Vanhommerg JW, Smulders NM, et al. Cold-activated brown adipose tissue in healthy men. N Engl J Med 2009; 360: 1500-8.

[26] Cypess AM, Lehman S, Willams G, et al. Identification and importance of brown adipose tissue in adult humans. N Engl J Med 2009; 360: 1509-17.

[27] Virtanen KA, Lidell ME, Orava J, et al. Functional brown adipose tissue in healthy adults. N Engl J Med 2009; 360: 1518-25.

[28] Ouellet V, Labbe SM, Blondin DP, et al. Brown adipose tissue oxidative metabolism contributes to energy expenditure during acute cold exposure in humans. J Clin Invest 2012; 122: 545-52.

[29] van der Lans AAJJ, Hoeks J, Brans B, et al. Cold acclimation recruits human brown fat and increases nonshivering thermogenesis. J Clin Invest 2013; 123: 3395-403.

[30] California Department of Fish and Wildlife. Shark encounters information: California white shark encounters. Updated April 22, 2013. Available online at: http://www.dfg.ca.gov/marine/whiteshark.a sp\#data

[31] Kay J. Rogue sea lion in S.F. menaces swimmers /marauding mammal bites at least 14, chases 10 from Aquatic Park Lagoon. San Francisco Chronicle November 16, 2006. Available online at: http://www.sfgate.c om/news/article/Rogue-sea-lion-in-S-F-menaces-swimmers-2483933.php

[32] Kolettis TM, Loettis MT. Winter swimming: healthy or hazardous? Evidence and hypotheses. Med Hypotheses 2003; 61: 654-6.

[33] Knott J. Are there benefits to cold water swimming? H2Open Magazine December, 2011. Available online at: http://jonathan-knott.com/2012/ 04/03/are-there-health-benefits-to-cold-water-swimming/

[34] Jansky L, Pospisilova D, Honzova S, et al. Immune system of coldexposed and cold-adapted humans. Eur J Appl Physiol Occup Physiol 1996; 72: 445-50

[35] Dugue B, Leppanen E. Adaptation related to cytokines in man: effects of regular swimming in ice-cold water. Clin Physiol 2000; 20: 114-21.

[36] Hermanussen M, Jensen F, Hirsch N, et al. Acute and chronic effects of winter swimming on LH, FHS, prolactin, growth hormone, TSH, cortisol, serum glucose and insulin. Arctic Med Res. 1995; 54: 45-51.

[37] Simes WG, Brenke R, Sommerburg O, Grune T. Improved antioxidative protection in winter swimmers. Q J Med 1999; 92: 193-6.

[38] Dugue B, Smolander J, Westerlund T. Acute and long-term effects of winter swimming and whole-body cryotherapy on plasma antioxidative capacity in healthy women. Scand J Clin Lab Invest 2005; 65: 395-402.

[39] Huttunen P, Kokko L, Virpi Y. Winter swimming improves general well-being. Int J Circumpolar Health 2001; 60: 400-6.

[40] VanHeest JL, Mahoney CE, Herr L. Characteristics of elite open-water swimmers. J Strength Cond Res 2004; 18: 302-5.

[41] Noakes TD, Dugas JP, Dugas LR, et al. Body temperatures during three long-distance polar swims in water of $0-3^{\circ} \mathrm{C}$. J Therm Biol 2009; 34: 23-31.

[42] Knechtle B, Christinger N, Kohler G, Kenchtle P, Roseman T. Swimming in ice cold water. Ir J Med Sci 2009; 178: 507-11.

(C) Nuckton et al.; Licensee Bentham Open.

This is an open access article licensed under the terms of the Creative Commons Attribution Non-Commercial License (http://creativecommons.org/licenses/by-nc/3.0/) which permits unrestricted, non-commercial use, distribution and reproduction in any medium, provided the work is properly cited. 